\title{
IMPLEMENTATION OF STUDENT-CENTRED EDUCATION PRINCIPLES IN A MASTER'S STUDY PROGRAMME: AN EXPLORATION OF THE EXPERIENCE OF ACADEMIC STAFF
}

\author{
Sanita Baranova, Baiba Kalı k̦e \\ University of Latvia, Latvia
}

\begin{abstract}
The paradigm shift in higher education pedagogy and policy has been a subject of discussion for 30 years, during which time the emphasis has been placed on the transition to studentcentred education. The implementation of this approach requires the democratisation of the study process and a shift towards performance-based outcomes, thus promoting students' research capacities, well-being, personal growth, and quality of life. The most important document on the subject, which was developed in collaboration with the leading organisations of the Bologna Process, is the Standards and Guidelines for Quality Assurance in the European Higher Education Area. This describes the common understanding of student-centred learning, teaching, and assessment. The standards and guidelines are also incorporated into the Latvian higher education quality assurance regulations.

The authors of the present study are involved in the development and approbation of a new master's study program, in which special attention is paid to the implementation of the principles of student-centred education. The central aim of the present study was to study the experience of lecturers in the implementation of the principles of student-centred education in the programme. The relevant literature and documents were surveyed and data from questionnaires (distributed to programme participants) were analysed.

Using the Standards and Guidelines for Quality Assurance in the European Higher Education Area and the Science, Technology Development and Innovation Guidelines 2021-2027 approved by the Latvian Ministry of Education and Science, the present study sets out 10 basic principles of student-centred education. A survey was created for lecturers who are implementing the newly created master's programme over one semester. Seventeen lecturers participated. The analysis of the questionnaire results indicated that promoting mutual respect in student-academic staff relations and students' active engagement in the study process were considered to be the most important principles. The results also revealed that lecturers applied every student-centred principle, but it is necessary to promote a common understanding by developing a mechanism for evaluating them and to improve the competence of teachers in implementing them.
\end{abstract}

Keywords: academic staff, higher education policy, implementation, master's study programme, student-centred education. 


\section{Introduction}

The issue of changing paradigms in higher education has been discussed in respect of tertiary pedagogy and higher education policy for 30 years. This discussion has emphasised the shift to student-centred study. To ensure and implement student-centred education, it is necessary to make the study process more democratic and move it towards performance-based outcomes, thus facilitating students' research capacities and wellness in the study process, as well as their personal growth and quality of life.

The most important document that has been developed in collaboration with the leading organisations of the Bologna Process is the Standards and Guidelines for Quality Assurance in the European Higher Education Area (2015). This outlines the common understanding of student-centred learning, teaching, and assessment. The standards and guidelines are also incorporated in the normative regulations for higher education quality assurance in Latvia and the internal normative documents of higher education institutions.

The scientific publications on the philosophical, pedagogical, and political aspects of the student-centred educational approach by Lynch (2016), Sadker and Zitleman (2017), Gover et al. (2019), and Trinidad (2019) formed the theoretical basis of the present study. Its authors are currently participating in the development and approbation of a new master's programme (called Education Sciences) in which great emphasis is placed on a student-centred approach. The introduction of student-centred education is connected with the organisational culture and a change of opinion among its members regarding every aspect of teaching and learning (Gover et al., 2019). The present study aimed to explore the experience of the academic staff in the introduction of student-centred education principles in the master's study programme in question. The central research question was: "How do the academic staff implement student-centred education principles on the master's study programme?"

\section{Method}

The present study adopted a mixed-method research design comprising the qualitative and quantitative analysis of the relevant scholarly literature and documents (i. e., sources) and questionnaires. Special attention was paid to the student-centred and research-based study process, where the process itself became the object. The present study makes a contribution to the literature on student-centred approaches in higher education programmes (Mārtinsone et al., 2016; Taber, 2016).

The study was based on the key principles of student-centred education as defined in the Standards and Guidelines for Quality Assurance in 
the European Higher Education Area (2015) and the Guidelines for the Development and Innovations of Science and Technologies 2021-2027 (Cabinet of Ministers, 2020), which were approved by the Latvian Ministry of Education and Science. The master's programme itself takes into account and respects students' interests and needs as a means of establishing appropriate learning paths to promote knowledge, skills, and competences; considers the different possible ways it may be implemented; applies diverse pedagogical methods and strategies, depending on the circumstances; encourages students' motivation and independence, and at the same time ensures guidance and support from the academic staff; facilitates mutual respect in student-staff relations, promoting an open and socially inclusive environment; and uses procedures for resolving students' complaints.

A survey was developed for the academic staff who have spent a term implementing the new master's programme; 17 participated. 15 respondents have a doctoral degree in educational management, pedagogy or psychology, two - a master's degree in educational management. The data collected were summarised and analysed using statistical and content analysis.

The questionnaire contained two questions: the first question with ten statements and the possibility to supplement the given statements (i. e., participants were given specific answer options and an opportunity to add their own). For the latter, participants were asked to give specific examples based on their experience of following the principles of student-centred education in their courses.

\section{Results}

The results of the present study were derived from the analysis of the empirical data. Student-centred learning (SCL) is an approach in higher education that focuses on students' learning needs to ensure the achievement of the intended learning outcomes. Student-centred learning ensures that the content of the study programme (including its structure and interactivity) reflects its aims and intended learning outcomes and that the methodology is appropriate (Gover et al., 2019; European Students' Union, 2015). Several related terms are used in the theoretical and methodological literature-the person-centred teaching-learning approach, the child-centred approach, and the pupil-centred approach-and each targets the learner at different ages and levels of education.

Student-centred learning is often understood differently in higher education, and it has been criticised within the academic discourse. This reveals a lack of understanding. Student-centred learning places a greater emphasis on the individuality of the student. It helps them to become aware of and understand their potential for success in changing circumstances. It is less 
structured than traditional approaches. It places less emphasis on previous academic experience. In SCL, the results to be achieved are determined in collaboration with the lecturer, and they depend on the current needs and interests of the student. The previous results of the study course and the programme are taken into account, and methods and techniques are jointly established (Lynch, 2016; Trinidad, 2019).

The European Students' Union, in its research study Overview on Student-Centred Learning in Higher Education in Europe (2015) stresses that SCL represents a shift in the culture and mindset of higher education institutions. It is a learning approach that is related to constructivist theories of learning. The European Students' Union established the theory on which SCL is based and the practice by which academic staff and students can implement SCL. It formulated nine SCL principles with the aim of providing a clearer understanding of SCL:

1. SCL is an ongoing reflexive process.

2. SCL does not have a one-size-fits-all solution.

3. Students have different learning styles.

4. Students have different needs and interests.

5. Choice is central to effective learning in SCL.

6. Students have different experiences and background knowledge.

7. Students should have control over their learning.

8. SCL is about enabling not telling.

9. Learning involves cooperation between students and staff.

The philosophical basis of SCL is formed by the theoretical findings of social constructivism, progressivism, and existentialism. In social constructivism, the goal is not only to form a generation of problem solvers but also to try to identify and eliminate problems that have arisen in society. The result to be achieved is to promote students' understanding of a society in which social injustice prevails, to value society and to reduce inequalities in it, and to create a new and fairer society (Sadker \& Zittleman, 2017). The theory of SCL emphasises the notion of students' individual action: they choose their goals; set social priorities; create action plans; and implement change (Lynch, 2016).

Progressivism is a student-centred theory of education. Individuality, change, and progress are prerequisites for education. Students learn best from what they consider most relevant in their lives (TheDigiTeachers, 2020), so in SCL, course programmes should be sufficiently flexible to take into account individual abilities, experience, needs, and interests when establishing course outcomes.

In education, the theory of existentialism manifests itself in students' self-directed learning, because the main question is whether students want to define who they are or whether they want society to define them. They 
should be allowed to develop their unique understanding of life, and this is one of the main results to be achieved (Lynch, 2016). Lecturers act as coordinators, helping to find the most appropriate methods and tools and allowing students to work on a variety of self-selected tasks at their own pace.

One of the most important principles of SCL is the promotion of mutual respect in student-academic staff relations. Students' diverse needs with regard to teaching methods and learning approaches, their active engagement in the study process, and the promotion of their self-reflection and independence through the staff's guidance and support are integral to the above-mentioned theories, which form the philosophical basis of SCL.

The methodology of the programme is based on the following:

1. Students can supplement the course content (i. e., they can develop an individualised plan).

2. Students have the opportunity to lead and take responsibility for learning (i. e., recommend and choose methods and techniques).

3. Students can personalise the pace at which they learn, using, for example, digital opportunities.

4. Several choices are provided in the assessment of the competencies acquired on the course.

5. The role of the lecturer as advisor is given greater emphasis (Heick, 2020).

By focusing on a student-centred approach, the university system and individual lecturers will be able to make the necessary changes to create an effective and life-transforming environment for students. Student-centred learning is generally described in terms of innovative methods of teaching that aim to promote learning in communication with academic staff and other students, and take students seriously as active participants in their own learning through the promotion of transversal skills (e. g., critical thinking, reflective thinking, and problem solving). Study processes should be described in terms of learning outcomes, thus giving students more responsibility in choosing their study paths and curricula. Students need to be engaged and motivated, but the foundational aspects of the facultystudent relationship in the academic environment should not be forgotten. Trinidad (2019) stated that there is a great deal of theoretical research on SCL in higher education that highlights key aspects and principles, but not of all of the findings have been scrutinised empirically (European Students' Union, 2015; Lynch, 2016).

The key principles of student-centred education that have been put forward based on the Standards and Guidelines for Quality Assurance in the European Higher Education Area (2015) can be observed in the development and implementation of the master's programme. The participants in 
the present study indicated which of these principles they follow in their practice. Figure 1 summarises their responses. They are presented in the order determined by the compliance of the principles with the internal logic of the development and implementation of the programme.

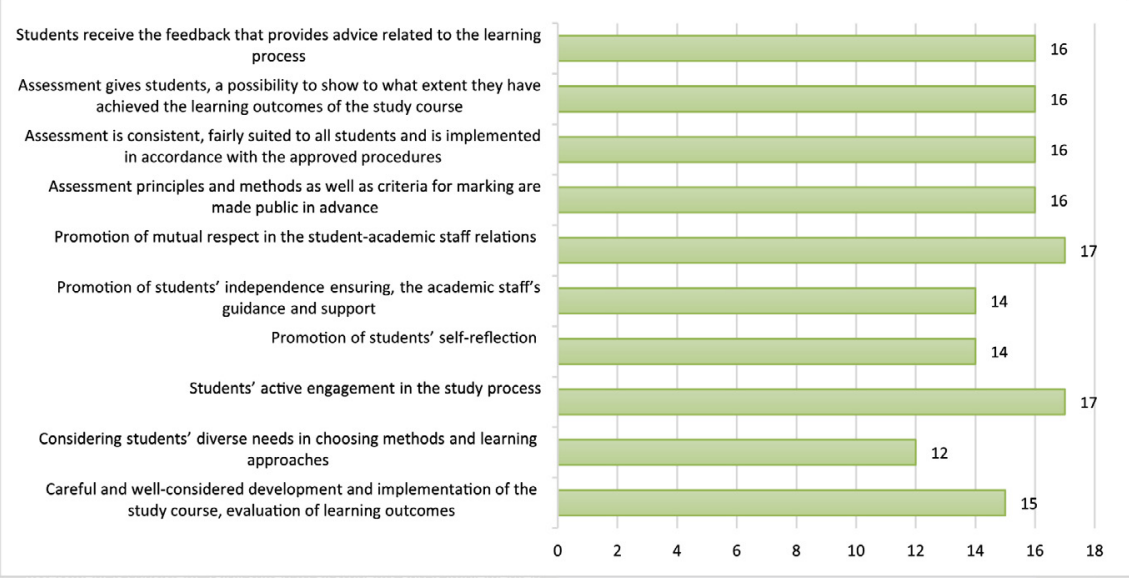

Figure 1. Student-Centred Education Principles in the Programme Study Courses

The principle a careful and well-considered development and implementation of the study course, evaluation of learning outcomes has been implemented since the beginning of the programme. First, the authors analysed characteristic indicators of the national economy of Latvia and trends of the current education policy implemented in the country; evaluated master's programmes in education sciences offered in Latvia and other countries of the world; and explored and conceptualised the needs of the target audience to formulate the aim and learning outcomes of the study programme and to ensure the succession of the content of each study course. An analysis of the learning outcomes of the courses and the experience of the academic staff revealed that purposeful acquisition of basic knowledge and skills was promoted; this will allow mastery of the intended competencies in the subsequent study process.

The principle considering students' diverse needs in choosing methods and learning approaches was evident in the incorporation within the overarching course of several subprogrammes: Pedagogy; Education Management; Teaching and Learning for Competence; Diversity and Inclusion in Education; and Human Behaviour and Education. Students had access to a voluminous literature at the University of Latvia Library. Different learning approaches were applied: visual, auditory, reading, and learning through doing. Accordingly, written and oral presentations, work with texts, case studies, situation analysis, 
role plays, and so on were used. The academic staff attempted to understand the everyday work needs of each student and adjust the modifiable content in lectures to these needs. Methods were adapted during the study process in accordance with the speed of students' perception and level of comprehension. They were subordinated to the real situation rather than previous decisions. Students had the option of choosing themes they were interested in. Despite the limitations of remote learning, the academic staff used pair work, group, and individual work requiring diverse tasks. These included reading and reflecting on texts; making presentations based on found materials; writing essays, carrying out project work in groups where each student was given a special responsibility. Some courses respected the time students needed for individual or group work. Students were given the opportunity to add to the prescribed sources of information.

Academic staff responses in the questionnaire emphasised students' active engagement in the study process, one of the most essential principles of student-centred education. They pointed out that they used a range of interactive methods, e. g., brainstorming, discussions, role-plays, presentations in groups, and case study analysis. The students led seminars, directed practical classes, and engaged in discussions. Their participation was encouraged, and they were given equal opportunities to participate in the study process.

One of the core values of the student-centred approach is the promotion of students' self-reflection. This is closely related to another principle of the programme - the promotion of students' independence ensuring the academic staff's guidance and support. The respondents stressed that self-reflection was a compulsory element of the course, and that assessment allowed for an understanding of the students' mindfulness, vision, and opinions. For instance, every student received descriptive feedback after each piece of independent work on the course Introduction to Education Science Studies. They had to search, analyse, reflect independently, and take responsibility for their initiative and outcomes when they carried out practical tasks. The staff supported students during lectures and tutorials by answering their questions.

The principle of promotion of mutual respect in the student-academic staff relations is a topical one in terms of the democratisation of the educational process. It requires the acknowledgement of abilities, knowledge, and values and taking into account different needs. The staff claimed that the atmosphere on the programme was open and calm and they regularly sought students' opinions and drew upon their experience. They found this sharing approach to be enriching. They also regarded students' peer learning as important. Different methods of communication were employed, and staff tried to ensure that these were always respectful. 
The following student-centred assessment principles must be abided by in the implementation of the programme:

1. Assessment principles and methods as well as criteria for marking are made public in advance.

2. Assessment is consistent, suited to all students, and implemented in keeping with the approved procedures.

3. Assessment gives students the opportunity to show that they have achieved the course learning outcomes.

4. Students receive feedback that offers advice related to the learning process.

As defined in the internal normative documents of the University of Latvia, students have to pass an examination at the end of every course in accordance with the requirements described in the course description. The latter must indicate how the results of interim tests and the final examination are distributed within the final score. The academic staff acquaint students with the course requirements and discuss them in a way that corresponds to the immediate circumstances. Students have access to more detailed assessment criteria in their e-study areas. Good practice in this regard was found on the course Introduction to Education Science Studies, on which evaluations were summarised, the most positive experiences were analysed, and mistakes were noted without any reference to students' names. The evaluations of the students' individual work were uploaded to the e-studies environment as separate documents.

Assessment allows students to exhibit the degree to which they have met the learning outcomes of the course. When several academic staff deliver courses, they evaluate the students' performance together to ensure fairness and objectivity. Students can consult with the staff if they are unclear about any issues. This assists in quality assurance. The consultations can take place via email, telephone, or Microsoft Teams.

\section{Discussion}

Although the questionnaire responses were positive towards SCL, they highlighted some serious problems and challenges. At present, SCL in Latvia is more substantiated in education policy documents than in in-depth pedagogical studies. The student-centred approach requires that learners' needs and activities are prioritised. For this to be achieved, lecturers need new competencies, which can be acquired through lecturer-centred continuing professional development. For example, when analysing the implementation of the principle of promotion of mutual respect in student-academic staff relations, it became clear that, while the respondents knew it necessary, it was not explicitly implemented (e. g., in terms of methods or 
techniques). It is conceivable that it was achieved indirectly, using pedagogical tact and ethics based on the lecturers' inner sense.

It is therefore necessary to promote a common understanding of SCL principles and a common mechanism of evaluation (Kim \& Davies, 2014). Institutional solutions for SCL implementation and collegial cooperation are also needed. In light of this, and having analysed the results of the academic staff questionnaire and the descriptions of the relevant study courses, we recommend that the course providers:

1. Diversify e-tools used in the remote study process (e. g., Mentimeter, Slido, Padlet, Google Drive, Linoit, and Miro).

2. Update and improve programmes on an ongoing basis.

3. Organise a seminar for academic staff on the programme to promote purposefully a common understanding of student-centred education principles.

4. Pay greater attention to the students' experience (including their experience of studying) and introduce more peer learning.

5. Provide more opportunities for individual (online) consultations as part of the remote study process.

6. Formulate the requirements of the course very precisely and focus on the culture of communication during lessons.

The present study revealed that, in general, the SCL was evaluated positively. However, future researchers should pay close attention to the over-simplification of certain aspects of the approach. A Finnish study by Saarinen and colleagues (2020) suggested that SCL could increase inequalities in learning outcomes if students' social and educational backgrounds are not taken into account, while researchers from Belgian universities (Baeten et al., 2013) have argued that SCL in higher education needs to make meaningful use of lecture-based and case-based approaches to ensure deeper learning.

\section{Conclusions}

A student-centred approach-the aim of which is to meet the needs and satisfy the interests of the target audience and achieve learning outcomesis one of the essential features of the paradigm shift in higher education. The present study has examined the experience of academic staff in their attempt to apply student-centred education principles to a master's study programme Education Sciences and has addressed the research question "How do the academic staff introduce student-centred education principles on the master's study programme?"

The analysis of the results of a questionnaire suggested that the staff took a positive view of SCL because the principles associated with it were 
observed in the study process. The most frequently implemented principles were the promotion of mutual respect in student-academic staff relations and students' active engagement in the study process. The findings, which also drew attention to the ambiguous and sometimes over-simplistic understanding of SCL, showed that there is a need to focus on the development of a common understanding of SCL at the institutional and programme level and to develop the methodological competence of lecturers in applying SCL principles. This should be carried out incrementally to ensure continuity and sustainability and to limit formalism in the process of implementation. When creating and developing study programmes, it is important for academic staff to have a deep understanding of how best to introduce SCL institutions in the context of organisational culture.

\section{References}

Baeten, M., Struyven, K., \& Dochy, F. (2013). Student-centred teaching methods: Can they optimise students' approaches to learning in professional higher education? Studies In Educational Evaluation, 39(1), 14-22. Retrieved from: https://www.researchgate. net/publication/257044591_Studentcentred_teaching_methods_Can_they_optimise_ students\%27_approaches_to_learning_in_professional_higher_education

Cabinet of Ministers (2020). Par Zinātnes, tehnologijas attīstības un inovācijas pamatnostādnēm 2021.-2027. gadam [On the Guidelines for Science, Technology Development, and Innovation 2021-2027]. Retrieved from: https://likumi.lv/ta/id/322468-par-zinatnestehnologijas-attistibas-un-inovacijas-pamatnostadnem-20212027-gadam

European Students' Union. (2015). Overview on student-centred learning in higher education in Europe. Research study. European Students' Union. Retrieved from: https://www.esuonline.org/wp-content/uploads/2016/07/Overview-on-Student-Centred-Learning-inHigher-Education-in-Europe.pdf

Gover, A., Loukkola, T., \& Peterbauer, H. (2019). Student-centred learning: Approaches to quality assurance. European University Association. Retrieved from: https://eua.eu/ downloads/publications/studentcentred\%20learning_approaches $\% 20$ to $\% 20$ quality $\% 20$ assurance\%20report.pdf

Heick, T. (2020). 15 examples of student-centered teaching. https://www.teachthought. com/pedagogy/15-examples-student-centered-teaching/

Kim, A. K., \& Davies, J. (2014). A teacher's perspective on student centred learning: Towards the development of best practice in an undergraduate tourism course. Journal of Hospitality, Leisure, Sport \& Tourism Education, 14, 6-14. https://www.sciencedirect. com/science/article/abs/pii/S1473837613000403?via\%3Dihub

Lynch, M. (2016). Philosophies of education: 3 types of student-centered philosophies. Retrieved from: https://www.theedadvocate.org/philosophies-education-3-types-studentcentered-philosophies/

Mārtinsone, K., Pipere, A., \& Kamerāde, D. (2016). Pētniecïba: Teorija un prakse [Research: Theory and practice]. Rìga: Raka.

Saarinen, A., Lipsanen, J., Hintsanen, M., Huotilainen, M., \& Keltikangas-Jarvinen, L. (2020). Student-oriented teaching practices and educational equality: A population-based study. Electronic Journal of Research in Educational Psychology, 18(51), 153-178. https:// doi.org/10.25115/ejrep.v18i51.2784 
Sadker, M., \& Zittleman, K. (2017). Teachers, schools, and society: A brief introduction to education ( $5^{\text {th }}$ ed.). New York: McGraw-Hill Higher Education.

Standards and Guidelines for Quality Assurance in the European Higher Education Area. (2015). Retrieved from: https://www.enqa.eu/wp-content/uploads/2015/11/ ESG_2015.pdf

Taber, K. S. (2016). Methodological issues in science education research. In A. M. Peters (Ed.), Encyclopedia of educational philosophy and theory (pp. 1-6). Springer Singapore. http://dx.doi.org/10.1007/978-981-287-532-7_35-1.

TheDigiTeachers (2020). Understanding the different types of teaching philosophies. https://thedigiteachers.com/teaching-philosophies/

Trinidad, J. E. (2019). Understanding student-centred learning in higher education: Students' and teachers' perceptions, challenges, and cognitive gaps. Journal of Further and Higher Education, 44(8), 1013-1023. https://www.tandfonline.com/doi/abs/ 10.1080/0309877X.2019.1636214?journalCode $=$ cjfh 20 